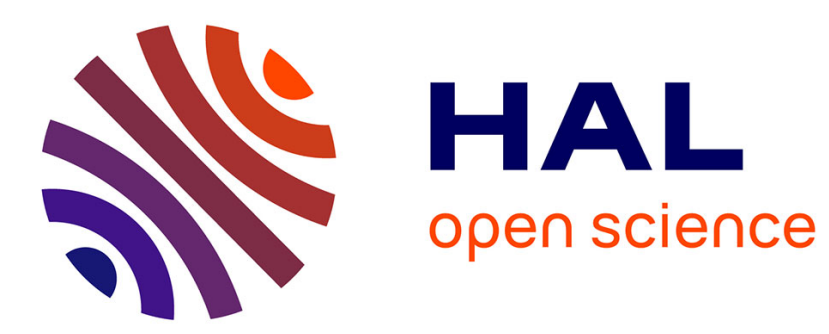

\title{
Electric and Thermal Model of Li-ion battery pack with cylindrical components
}

Khadija Saqli, Bouchareb Houda, Nacer K M'Sirdi, Aziz Naamane, Mohammed Oudghiri

\section{- To cite this version:}

Khadija Saqli, Bouchareb Houda, Nacer K M’Sirdi, Aziz Naamane, Mohammed Oudghiri. Electric and Thermal Model of Li-ion battery pack with cylindrical components. REDEC'20 the International Conference on Renewable Energy for Developing Countries, Mar 2020, Marrakech, Morocco. hal02486435

\section{HAL Id: hal-02486435 \\ https://hal.science/hal-02486435}

Submitted on 21 Feb 2020

HAL is a multi-disciplinary open access archive for the deposit and dissemination of scientific research documents, whether they are published or not. The documents may come from teaching and research institutions in France or abroad, or from public or private research centers.
L'archive ouverte pluridisciplinaire HAL, est destinée au dépôt et à la diffusion de documents scientifiques de niveau recherche, publiés ou non, émanant des établissements d'enseignement et de recherche français ou étrangers, des laboratoires publics ou privés. 


\section{Electric and Thermal Model of Li-ion battery pack with cylindrical components}

\author{
$1^{\text {st }}$ Khadija SAQLI \\ Sidi Mohamed Ben Abdellah University \\ National School of Applied Sciences \\ Fez, Morocco, \\ khadija.saqli@usmba.ac.ma
}

\author{
$2^{\text {nd }}$ Houda BOUCHAREB \\ Sidi Mohamed Ben Abdellah University \\ National School of Applied Sciences \\ Fez, Morocco, \\ houda.bouchareb@usmba.ac.ma
}

\author{
$3^{\text {th }}$ Kouider Nacer M'sirdi \\ LiS, Aix Marseille University \\ Marseille, France \\ nacer.msirdi@lis-lab.fr address \\ https://orcid.org/0000-0002-9485-6429
}

\author{
$4^{\text {rd }}$ Aziz NAAMANE \\ LiS Aix Marseille University \\ Marseille, France \\ aziz.naamane@lis-lab.fr
}

\author{
$5^{\text {th }}$ Mohammed OUDGHIRI \\ Sidi Mohamed Ben Abdellah University \\ National School of Applied Sciences \\ Fez, Morocco, \\ oudghiri.ensafes@gmail.com
}

\begin{abstract}
In this paper, a Lithium-Ion battery pack is analyzed, modelled and simulated under the $\mathrm{Comsol}^{\circledR}$, Software package. Two cooling methods are investigated in this paper : air-cooling approach and direct liquid cooling approach. This physical oriented model allows to understand the rationale behind the battery pack dynamics and choose an equivalent circuit model which can be used for the State Of Charge (SOC) estimation, the heat prediction and the battery thermal management and control.

Index Terms-Li-ion, Thermal management system, aircooling, direct liquid cooling, equivalent circuit model, heat prediction.
\end{abstract}

\section{INTRODUCTION}

The global need for clean and renewable power generation that can respond the best to the rising concerns of fuel consumption has encouraged the use of energy storage systems. The literature has presented different categories of batteries with different characteristics and capacities [1]-[3]. The high energy density and lightweight of Li-ion batteries have allowed them to domination the energy storage market, especially for automotive applications [4].

Safe operation of Li-ion batteries requires the management of its temperature evolution during charge and discharge. High temperatures can damage the energy storage system or even cause an explosion, while low temperatures can lead to irreversible damage to the battery [5]. Therefore, an optimal range of $15^{\circ} \mathrm{C}$ to $35^{\circ} \mathrm{C}$ should be maintained for proper operation of the Li-ion battery [6].

A thermal management system capable of dissipating the generated heat is of vital importance for Li-ion batteries. A proper cooling approach can help to manage the thermal behaviour of the cells, increase the safety and their life span. It assures an even temperature distribution inside the battery pack to avoid localized deterioration, and dissipates the generated heat to maintain the optimum range of temperature inside the battery pack [7]. A proper cooling method can increase safety and improve battery lifespan.
Different cooling approaches with different complexity level and cost, have been proposed in literature. Forced air cooling is the simplest and most used approach to reduce the temperature of the energy storage system [8]. For low-density batteries are cooled either by natural or using forced convection. The low heat air capacity causes its temperature to rise when used to cool series-connected cells. Thus, the outermost cells are not well cooled, leading to an uneven temperature distribution [9]. These limitations can be addressed by taking some measurement when building the battery pack, such as the battery size and the arrangement of the cells.

Another common approach to manage the temperature is liquid cooling. Compared to air, liquid coolant has higher density and heat capacity, which make it more effective in removing the generated heat with relatively low flow rates [10]. Liquid cooling can be grouped into two main categories direct and indirect cooling, depending on how the liquid coolant is applied. When using a direct liquid cooling, the cells of the battery pack are immersed in the coolant liquid, which offers a (quasi) uniform temperature distribution. However, the major concern with this kind of cooling approach is the short-circuit potential caused by electrical conduction between the coolant and the cells. Hence, indirect liquid cooling is used to mitigate the heat and avoid short-circuits. This kind of approach has been adopted by different electric vehicle manufacturers, thanks to its high thermal conductivity.

Despite the high efficiency of liquid cooling methods to mitigate the generated heat and assure an even temperature distribution inside the battery pack, it suffers from several drawbacks that limit its use, such as cost, weight, complexity and potential leaks.

Phase change material (PCM) is one of the common thermal management methods used to cool the pack cells. During operation, the phase change material absorbs the generated heat to maintain the ambient temperature of the battery pack at the optimum range [11]. PCM has a melting point that 
should not be exceeded for normal operation. This makes this method unsuitable for long time operation or when the ambient temperature is too high or too cold. Different factors can affect the thermal performance of the battery. Numerous thermal models with different cooling methods were developed in the literature. Dafen Chen et al. in [19] studied and compared the efficiency of air-cooling, direct-cooling, indirect-cooling and fin cooling. They found that indirect-cooling has the lest temperature rise compared to the other methods. Naixing Yang et al. studied in [17] the impact of battery design and cell layout on the thermal performance of the battery. G. Karimi and X. Li [18] review the relationship between the generated heat and design parameters. They found that an even temperature distribution can be achieved by using forced convection to dissipate the generated heat.In [20], H. Park used forced air method to manage the thermal behaviour of the battery for hybrid electrical vehicles. The author proves that the usage of a tapered manifold and pressure relief ventilation can improve the cooling efficiency of the thermal model.

In this paper, we study the thermal management system of three Li-ion cells connected in series (18650) based on an indirect liquid cooling system. The aim was to study the thermal performance of this cooling approach, the heat generated per cell and the temperature distribution.

\section{BATTERY MODEL}

Battery modelling allows a better understanding of the physics and the electrochemical reactions of the battery that occur during operation. A good model can improve the accuracy of the battery states estimation and thus, its lifespan. Different battery models have been proposed in literature. The complexity and accuracy of the models depend on the application target. In general, battery models can be classified into two main categories, that are Electrochemical Models (EM) and Equivalent Circuit Models (ECM).

Electrochemical models, also known as pseudo-twodimension(P2D) models, is a complex representation of the battery. Based on physical laws such as Ohm's law, the BulterVolmer law and Fick's law of diffusion, this category uses a set of Partial Differential Equations (PDE) to represents the inner electrochemical reactions that take place during operation [12]. The first complete electrochemical battery model was developed by Doyle and Newman. The Newman model has been validated by different scientists. It uses MaxwellStefan equations for the ions transport in concentrated binary electrolytes [13], [14].

The high computational power needed by this type of models to solve the model equations makes them inadequate for real-time applications. To reduce the calculation cost, researchers have proposed to transform the PDEs equations into Ordinary Differential Equations (ODEs) using different numerical equations, such as Finite Element Method and Finite Difference Method [15].

Equivalent Circuit Models (ECM) use electrical components to describe the battery behaviour in response to a certain current load. The simplicity and acceptable accuracy of this type of models have gained them large popularity, for real-time applications [16].

Typically, an ECM includes an open circuit voltage (OCV), a series resistor for voltage bias, and one or more RC blocks to represent the dynamic response of the battery to a change in input current (Fig. 1).

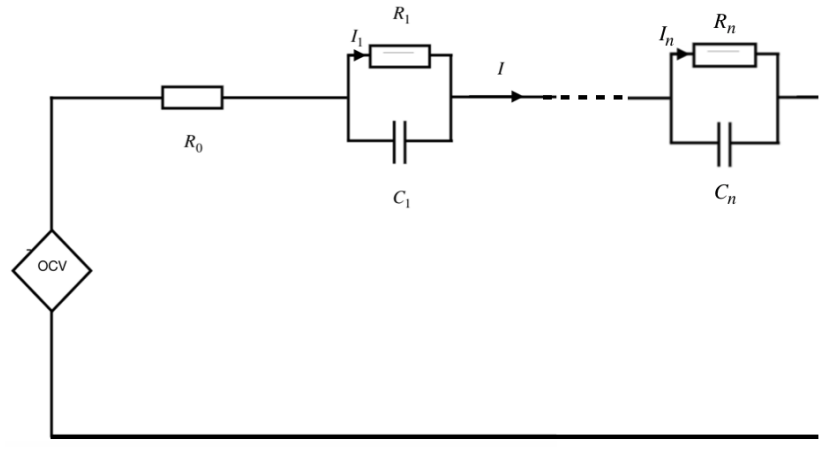

Fig. 1. $\mathrm{n}$ order equivalent circuit model.

In this study, a 18650 cylindrical Li-ion battery is considered. The dimension and thermophysical parameters of the cells are listed in table III The battery pack consists of three cells linked together in parallel using small connecting strips placed at the top and the bottom of each cell as shown in Fig. 2

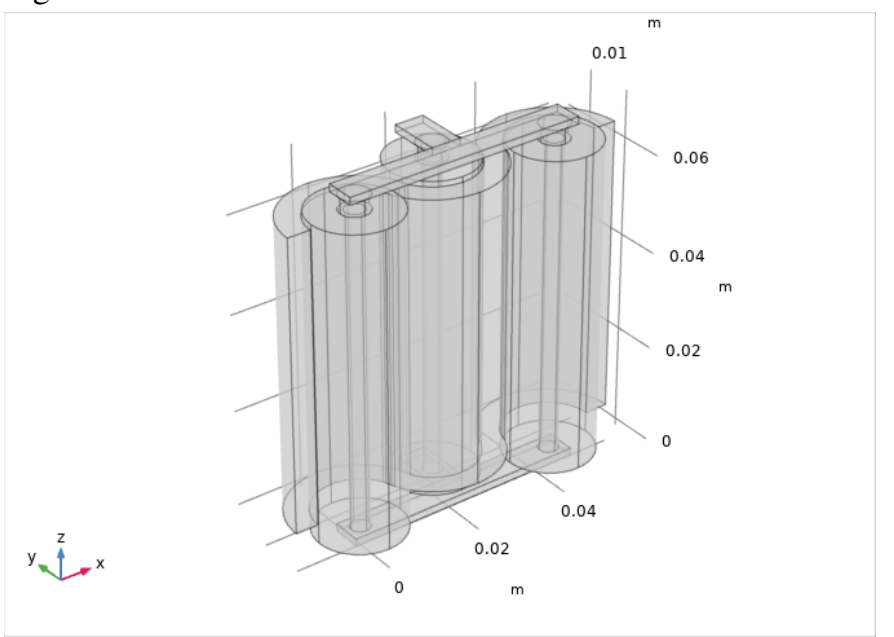

Fig. 2. Battery pack geometry.

\begin{tabular}{|c|c|}
\hline Dimensions and properties & $\mathbf{1 8 6 5 0}$ cell \\
\hline Diameter & $18 \mathrm{~mm}$ \\
\hline Height & $65 \mathrm{~mm}$ \\
\hline Capacity & $2.5 \mathrm{Ah}$ \\
\hline Density & $2055.2 \mathrm{~kg} / \mathrm{m}^{3}$ \\
\hline Heat capacity & $1399.1 \mathrm{~J} /(\mathrm{kg} . \mathrm{K})$ \\
\hline Thermal conductivity, radial & $0.89724 \mathrm{~W} /(\mathrm{m} . \mathrm{K})$ \\
\hline
\end{tabular}

TABLE I

DIMENSIONS AND THERMO-PHYSICAL PARAMETERS

A cylindrical Li-ion battery consists of a can containing layers of the cathode, an anode and separators rolled into a cylinder as illustrated in Fig. 3 .

To develop an electro-thermal model with indirect cooling, we used COMSOL Multi-physics software. The model was constructed in two phases. First using Batteries and Fuel 


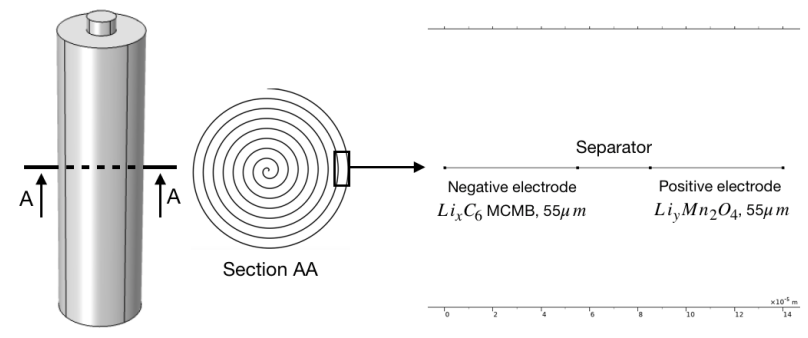

Fig. 3. Configuration of the cylindrical Li-ion battery cell.

Cells library, the inner electrochemical reactions of the battery were modelled in 1D. Then, we built our geometry in $3 \mathrm{D}$ to simulate the heat generation of the cells and the performance of the thermal management system using the Heat Transfer in Solids and Fluids. The two models are paired using a coupling function to link the electrochemical model to the thermal model by the average generated heat and the average temperature.

The 1D geometrical model as shown in Fig. 3 consists of a negative electrode, a separator and a positive electrode, based on the Newman model the electrochemical reactions that occur at each section of the cell during operation are presented according to physics laws using Partial Differential Equations (PDEs). A full derivation of the electrochemical model is too complex to be elaborated in this paper. However, the governing equations and boundary conditions are provided in table $\Pi$.

The three-dimensional model is used to model the thermal behaviour of the cells and the coolant flowing through the cells. The generated heat is dissipated using wavy tubes of aluminium placed between the cells of the battery pack as illustrated in Fig. 4

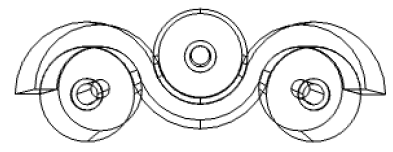

Fig. 4. Geometry of tube cooling system.

To capture the thermal behaviour of the cells and test the efficiency of the proposed thermal model, the battery pack was charged/discharged continuously for 1500s using an alternating current at $7.5 \mathrm{C}$ rate, followed by a relaxation period of 900s. The density and the heat capacity are considered the same for all the cells and the heat generation of the cells is calculated using the following equations:

$$
\left\{\begin{array}{l}
\frac{\partial \rho C_{p} T}{\partial t}-\nabla \cdot(k \nabla T)=Q \\
Q=\sigma_{e f f, p} \nabla^{2} \phi_{s, p}+\sigma_{e f f, n} \nabla^{2} \phi_{s, n}+J\left[U-\left(\phi_{s, p}-\phi_{s, n}\right)-\right.
\end{array}\right.
$$

Where $C_{p}$ is the heat capacity, $\mathrm{T}$ is the temperature, $\mathrm{k}$ is the thermal conductive coefficient, $\mathrm{Q}$ is the generated heat and $\mathrm{U}$ is the open circuit voltage of the battery. The cells state of charge is initially set at $10 \%$, the initial temperature at $25{ }^{\circ} \mathrm{C}$ and the liquid coolant velocity at $0.1 \mathrm{~m} / \mathrm{s}$.
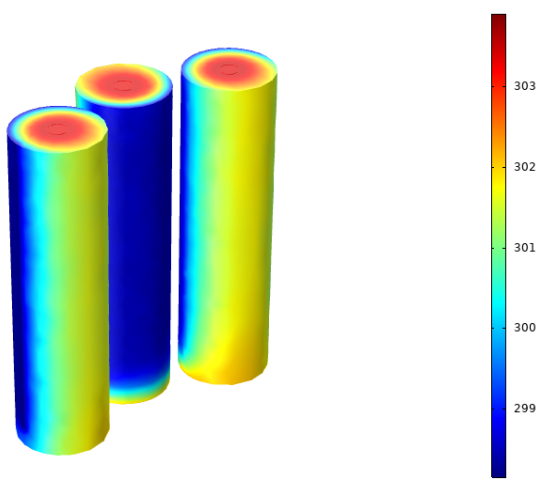

Fig. 5. Temperature distribution in the cells with tube cooling.

Fig. 5 illustrates the temperature distribution inside the model at 594s. As the fluid passes through the channel, it absorbs the heat generated by the cells. As a result, the temperature of the cells decreases and stays within the safety range of operation.

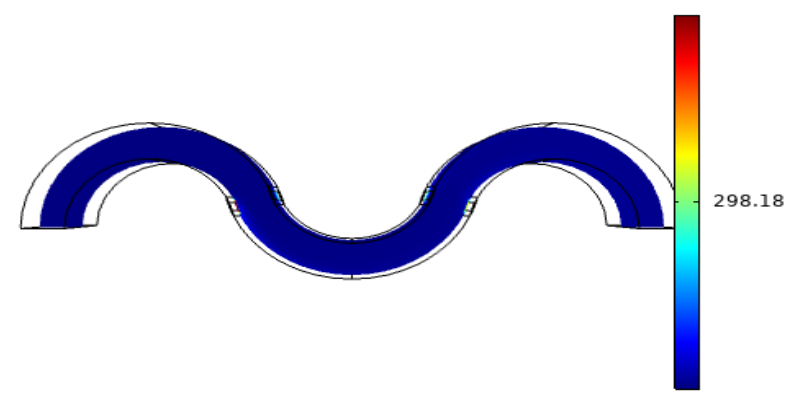

Fig. 6. Coolant temperature.

Fig.6 6illustrates the temperature of the liquid coolant during the simulation. For this study where we used a small battery pack with three cells, the developed thermal system with tubecooling was able to keep the temperature of the cells at the optimal range of operation with an insignificant change of the coolant temperature, which makes this thermal management system suitable for larger battery packs.

To illustrate the impact of the chosen cooling method on the temperature distribution in the battery pack, we developed another thermal model for the same system based on aircooling. The three same cells were placed in a compartment where the air flows to dissipate the generated heat. Various tests were conducted with different inlet velocity and cell's arrangement to find the optimum conditions needed to keep the Li-ion cells at their optimal range.

Fig. 7 displays the simulation results for the air-cooling method at three different inlet velocity ((a) $6 \mathrm{~m} / \mathrm{s}$, (b) $1 \mathrm{~m} / \mathrm{s}$ and (c) $0.1 \mathrm{~m} / \mathrm{s}$ ). For the direct liquid cooling, an inlet velocity - of $\frac{\$ 5}{d T} 1 \mathrm{~m} / \mathrm{s}$ was sufficient to keep the temperature of the three cells under $304 \mathrm{~K}$, for the same conditions the air-cooling method was incapable of dissipating the generated heat, the temperatures of the cells have exceeded the permissible limits to $321 \mathrm{~K}$.

For air-cooling, a minimum inlet velocity of $6 \mathrm{~m} / \mathrm{s}$ is required to keep the cell's temperature distribution at the optimal range 
TABLE II

Model Equations and Boundary Conditions of THE P2D Model.

\begin{tabular}{lll}
\hline Description & Govering equations & Boundary conditions \\
\hline $\begin{array}{l}\text { Diffusion } \\
\text { solid }\end{array}$ & inside the $\frac{\partial c_{s}}{\partial t}=\frac{D_{s}}{r^{2}} \frac{\partial}{\partial r}\left[r^{2} \frac{\partial c_{s}}{\partial r}\right]$ & $-\left.D_{s} \frac{\partial c_{s}}{\partial r}\right|_{r=0}=0,-\left.D_{s} \frac{\partial c_{s}}{\partial r}\right|_{r=R_{p}}=j_{k}$
\end{tabular}

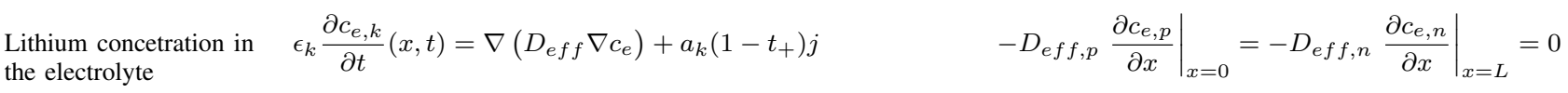
the electrolyte

Potential in the solid $\nabla\left(\sigma_{e f f} \nabla \phi_{s, k}\right)=a_{k} F j_{k}$ phase

Potential in the electrolyte phase

$$
\begin{aligned}
&-\nabla\left(\sigma_{e f f, k} \nabla \phi_{e}\right)+\frac{2 R T}{F}\left(1-t_{+}\right) \nabla\left(k_{e f f, k} \nabla \ln c_{e}\right)+J=0\left.\frac{\partial \phi_{e}}{\partial x}\right|_{x=L_{n}}=0 \\
&\left.\frac{\partial \phi_{e}}{\partial x}\right|_{x=L_{p}}=0
\end{aligned}
$$

Pore wall flux

overpotential of the intercalation reaction

$$
\begin{aligned}
& -\left.\sigma_{e f f, p} \nabla \phi_{s, p}\right|_{x=0}=0 \\
& -\left.\sigma_{e f f, n} \nabla \phi_{s, n}\right|_{x=L}=I \\
& -\left.\sigma_{e f f, p} \nabla \phi_{s, p}\right|_{x=L_{p}}=-\left.\sigma_{e f f, n} \nabla \phi_{s, n}\right|_{x=L_{p}+L_{s e p}}=0
\end{aligned}
$$

where they can operate properly, as shown in Fig. 7)(a).

\section{SECond-ORder Equivalent Circuit MOdEL IDENTIFICATION}

The low computational cost and acceptable accuracy of ECM have encouraged their use for EV application. A secondorder equivalent circuit model (Fig. 8) is selected in this paper for its practicality and high accuracy [21]. As illustrated in figure 7, the selected model comprises an OCV as the battery open-circuit voltage, $\mathrm{R}$ as the battery internal resistance and two RC blocks to represent the battery polarization caused by diffusion, transfer and other factors.

The following equations represent the characteristics of the model:

$$
\begin{gathered}
\frac{d I_{1}(t)}{d t}=-\frac{1}{R_{1} C_{1}} I_{1}(t)+\frac{1}{R_{1} C_{1}} I(t) \\
\frac{d I_{2}(t)}{d t}=-\frac{1}{R_{2} C_{2}} I_{2}(t)+\frac{1}{R_{2} C_{2}} I(t) \\
\frac{d S O C(t)}{d t}=-\frac{\eta(t)}{Q} I(t)
\end{gathered}
$$

$$
U_{t}=O C V(S O C(t))-R_{0} I(t)-R_{1} I_{1}(t)
$$

Where $\mathrm{I}(\mathrm{t}), I_{1}(t), I_{2}(t)$ denote respectively the current across the ohmic resistance R0, R1 and R2, SOC is the battery state of charge, $\eta$ is the coulomb efficiency used to compensiate the lost of charge and Q is the battery capacity.

To be able to capture the instantaneous and the dynamic response of the battery to a current load, we need first to identify the equivalent circuit model parameters that are the open-circuit voltage, internal resistance and RC blocks. There are different methods and algorithms to identify model parameters such as neural network, least squares and Kalman filtering.

To build this model, the electrochemical battery model presented in the previous section was discharged by a $7.5 \mathrm{~A}$ pulse current (Fig. 9). The Li-ion battery was considered in a full charge state and the initial temperature was set at $15^{\circ} \mathrm{C}$. The second-order ECM was developed in Matlab Simulink. Each component of the circuit was customized using Simscape language to account for the battery state of charge. To predict 
(a)

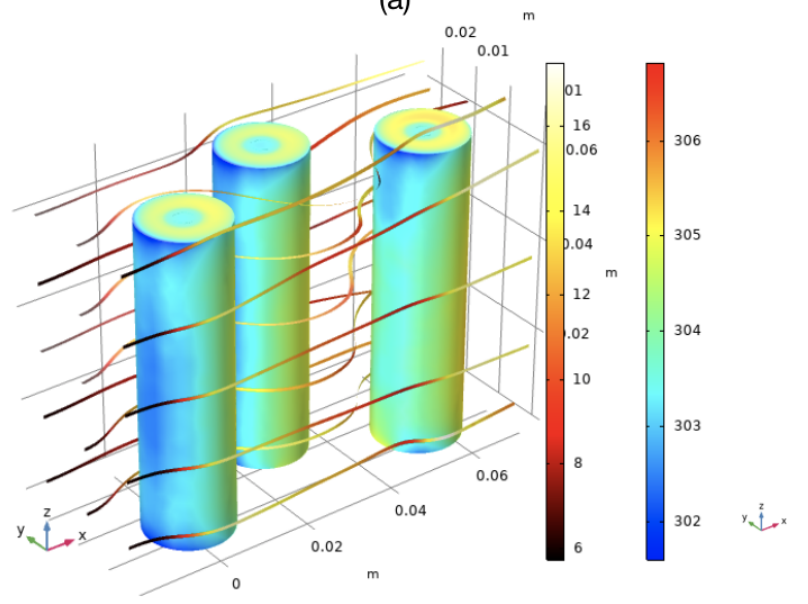

(b)

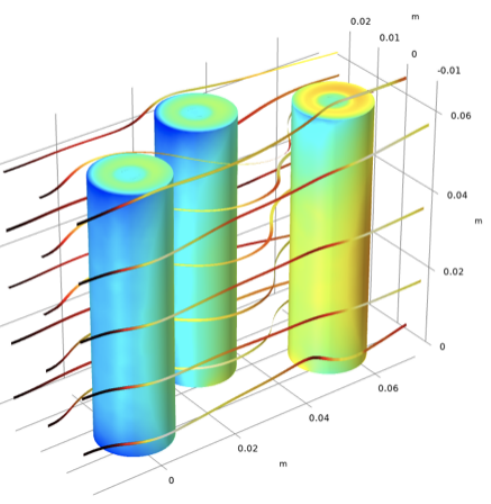

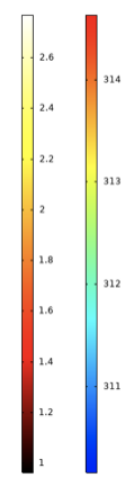

(c)

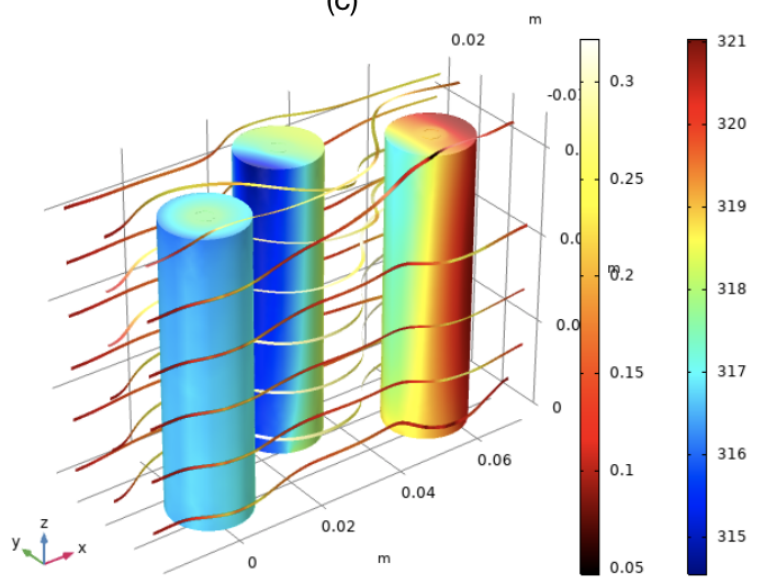

Fig. 7. Temperature distribution in the pack with (a):inlet velocity set at $6 \mathrm{~m} / \mathrm{s}$, (b):inlet velocity set at $1 \mathrm{~m} / \mathrm{s}$, (c):inlet velocity set at $0.1 \mathrm{~m} / \mathrm{s}$.

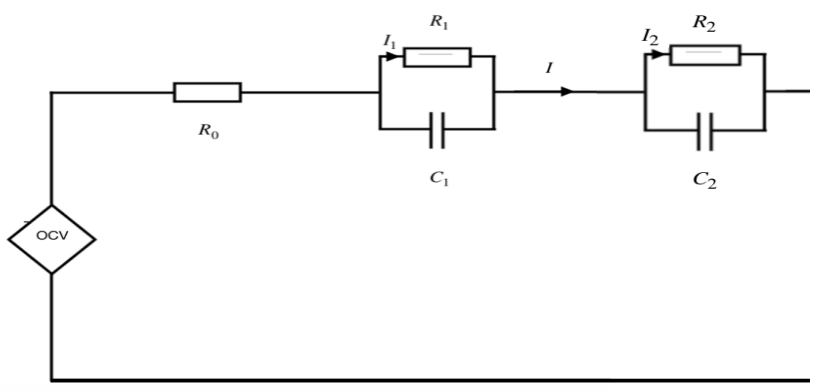

Fio 8 Serond order emivalent sirmit model

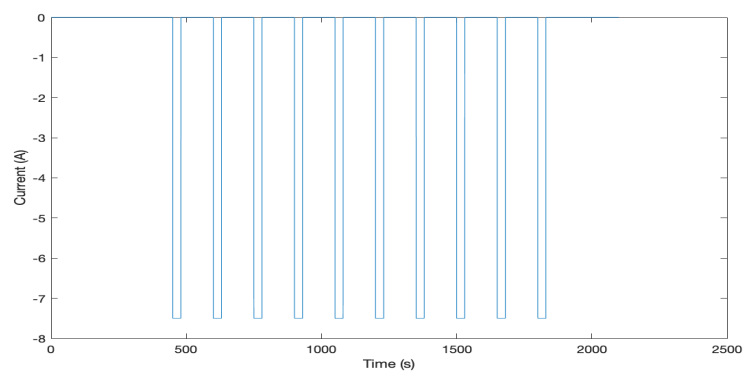

Fig. 9. Current pulse.

the battery parameters we used the least square method for its high accuracy and simplicity.

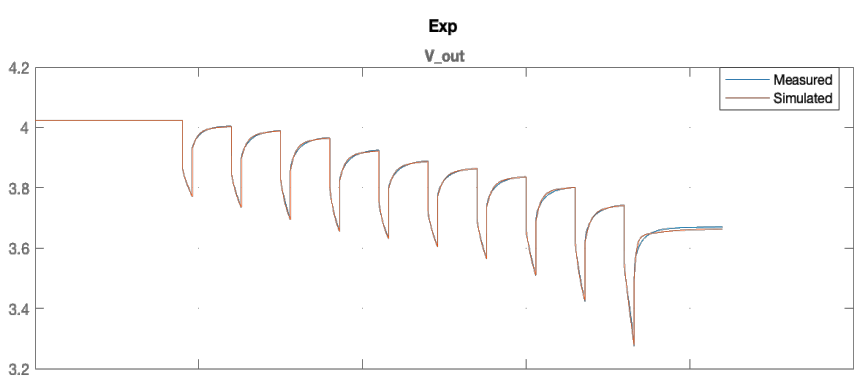

Fig. 10. Measured versus simulated output voltage of the second order ECM.

(Fig. 10 illustrates the agreement between the simulated and measured output voltage of the equivalent circuit model after the estimation process ends. At the end of the simulation the relative sum square error change by $r=5.33 \mathrm{e}-05$, which shows the ability of the developed equivalent circuit model to emulate with accuracy the instantaneous dynamic behaviour of the battery cell during operation.

\section{CONCLUSION}

In the present study, an electrochemical-thermal model for a battery pack of three 18650 cylindrical cells was built using COMSOL Multiphysics. Two cooling methods were 
developed and analyzed on the model:air-cooling and tubecooling method. The performance and thermal efficiency of each method were compared. The simulation results showed that the proposed tube-cooling is more efficient and was able to maintain the temperature of the cells at the optimal range of operation with an inlet velocity of $0.1 \mathrm{~m} / \mathrm{s}$.

The developed electrochemical-thermal model was then used to build a second-order equivalent circuit model in Matlab.

The goal of this study was first to develop an efficient thermal management system that can assure the proper operating condition for a Li-ion battery pack and couple the model to build an enhanced electrical model that can be used to provide accurate estimation of the battery states, like the battery State Of Charge (SOC) and State Of Health (SOH). The model can be further improved to account for other degradation factors such as hysteresis, that impact battery performance.

\section{NOMENCLATURE}

\section{Subscripts}

$\begin{array}{ll}e & \text { electrolyte } \\ \text { eff } & \text { effective } \\ \max & \text { maximum } \\ n & \text { negative } \\ p & \text { positive } \\ s & \text { solid } \\ \text { sep } & \text { separator } \\ \text { surf } & \text { surface }\end{array}$

\section{List of symbols}

\section{$\epsilon$ porosity}

$\eta \quad$ overpotential of the intercalation reaction, $\mathrm{V}$

$\rho$ density, $\mathrm{kg} \mathrm{m}^{-3}$

$\sigma_{i} \quad$ electronic conductivity of solid matrix, $\mathrm{S} m^{-1}$

$a_{s} \quad$ reaction surface area, $m^{2} m^{-3}$

$C_{p} \quad$ specific heat, $\mathrm{J} \mathrm{kg}^{-1} \mathrm{~K}^{-1}$

$c_{s} \quad$ concentration of lithium ion in solid, mol $m^{-3}$

$D_{e} \quad$ salt diffusion coefficient, $m^{2} s^{-1}$

$D_{s} \quad$ diffusion coefficient of lithium ion in solid electrode

$F \quad$ Faraday's constant, $\mathrm{C} \mathrm{mol}^{-1}$

$J \quad$ pore wall flux of lithium ions, mol $m^{-2} s^{1}$

$k_{i} \quad$ reaction rate, $m^{2.5} \mathrm{~mol}^{-0.5} \mathrm{~s}^{-1}$

$L \quad$ thickness of battery component

$R \quad$ gas constant, $\mathrm{J} \mathrm{mol}^{-1} K^{-1}$

$r \quad$ radial coordinate in spherical particle

$T$ temperature, $\mathrm{K}$

$t$ time, s

$t_{+} \quad$ transference number of lithium ion

$U$ open-circuit potential, $\mathrm{V}$

$x \quad$ spatial coordinate

\section{REFERENCES}

[1] Haoyi Yang, Feng Wu, Ying Bai, Chuan Wu, "Toward better electrode/electrolyte interfaces in the ionic-liquid-based rechargeable aluminum batteries," Journal of Energy Chemistry, Volume 45, June 2020, Pages 98-102.
[2] Zhaoqiang Zhu, Ruizhi Zhang, Jiahao Lin, Kefu Zhang, Nan Li, Chunhua Zhao, Guorong Chen, Chongjun Zhao, "Ni,Zn-codoped MgCo2O4 electrodes for aqueous asymmetric supercapacitor and rechargeable $\mathrm{Zn}$ battery", Journal of Power Sources, Volume 437, 15 October 2019, Article 226941.

[3] Jilei Liu, Chaohe Xu, Zhen Chen, Shibing Ni, Ze Xiang Shen, 'Progress in aqueous rechargeable batteries", Green Energy \& Environment, Volume 3, Issue 1, January 2018, Pages 20-41.

[4] Ghassan Zubi, Rodolfo Dufo-López, Monica Carvalho, Guzay Pasaoglu, "The lithium-ion battery: State of the art and future perspectives Renewable and Sustainable Energy Reviews", Volume 89, June 2018, Pages 292-308.

[5] Rui Zhao, Sijie Zhang, Jie Liu, Junjie Gu, "A review of thermal performance improving methods of lithium ion battery: Electrode modification and thermal management system", Journal of Power Sources, Volume 299, 20 December 2015, Pages 557-577.

[6] Dafen Chen, Jiuchun Jiang, Gi-Heon Kim, Chuanbo Yang, Ahmad Pesaran , "Comparison of different cooling methods for lithium ion battery cells", Applied Thermal Engineering, Volume 94, 5 February 2016, Pages 846-854.

[7] Huaqiang Liu, Zhongbao Wei, Weidong He, Jiyun Zhao, "Thermal issues about Li-ion batteries and recent progress in battery thermal management systems: A review", Energy Conversion and Management, Volume 150, 15 October 2017, Pages 304-330.

[8] Shahabeddin K. Mohammadian, Yuwen Zhang, "Thermal management optimization of an air-cooled Li-ion battery module using pin-fin heat sinks for hybrid electric vehicles", Journal of Power Sources, Volume 273, 1 January 2015, Pages 431-439.

[9] Han, T., Khalighi, B., Yen, E. C., and Kaushik, S. ,'Li-Ion Battery Pack Thermal Management: Liquid Versus Air Cooling." ASME. J. Thermal Sci. Eng. Appl. April 2019; 11(2): 021009.

[10] X. Guodong, C. Lei and B. Guanglong, "A review on battery thermal management in electric vehicle applicaion," Journal of Power Sources, pp. 90-105, 2017.

[11] G.-H.Kim,J.Gonder,J.Lustbader,A.Pesaran, "Thermal management of batteries in advanced vehicles using phase-change materials", World Electr. Veh. J. 2 (2008) 134-147.

[12] Meng, J., Luo, G., Ricco, M., Swierczynski, M., Stroe, D.-I. and Teodorescu, R. (2018). Overview of Lithium-Ion Battery Modeling Methods for State-of-Charge Estimation in Electrical Vehicles. Applied Sciences, 8(5), 659.

[13] Doyle, M.; Fuller, T.F; Newman, J. Modeling of galvanostatic charge and discharge of the lithium polymer insertion cell. J. Electrochem. Soc. 1993, 140, 1526-1533.

[14] Doyle, M.; Fuller, T.F.; Newman, J. Simulation and optimization of the dual lithium ion insertion cell. J. Electrochem. Soc. 1994, 141, 1-10

[15] Forman, J.C.; Bashash, S.; Stein, J.L.; Fathy, H.K. Reduction of an Electrochemistry-Based Li-Ion Battery Model via Quasi-Linearization and Padé Approximation. J. Electrochem. Soc. 2011, 158, A93.

[16] ElMin Chen, and Gabriel A. Rincon-Mora. Ectrical Battery Model Capable of Predicting Runtime and I-V Performance. (2006). IEEE TRANSACTIONS ON ENERGY CONVERSION, 21, 504-511.

[17] Yang, N., Zhang, X., Li, G., and Hua, D. (2015). Assessment of the forced air-cooling performance for cylindrical lithium-ion battery packs: A comparative analysis between aligned and staggered cell arrangements. Applied Thermal Engineering, 80, 55-65.

[18] Karimi, G., and Li, X. (2012). Thermal management of lithium-ion batteries for electric vehicles. International Journal of Energy Research, 37(1), 13-24.

[19] Chen, D., Jiang, J., Kim, G.-H., Yang, C., and Pesaran, A. (2016). Comparison of different cooling methods for lithium ion battery cells. Applied Thermal Engineering, 94, 846-854.

[20] Park, H. (2013). A design of air flow configuration for cooling lithium ion battery in hybrid electric vehicles. Journal of Power Sources, 239, 30-36.

[21] Si Li, Ximing Cheng. (2014). A comparative study on RC models of lithium-ion battery. 2014 IEEE Conference and Expo Transportation Electrification Asia-Pacific (ITEC Asia-Pacific). 